\title{
CONCENTRATION COMPACTNESS PRINCIPLES FOR THE SYSTEMS OF CRITICAL ELLIPTIC EQUATIONS
}

\author{
DONGSHENG KANG
}

Abstract. In this paper, some important variants of the concentration compactness principle are established. By the variants, some kinds of the elliptic systems can be investigated and the existence of nontrivial solutions to the systems can be verified by the variational methods.

Mathematics subject classification (2010): 35B33, 35J45, 35J50.

Keywords and phrases: concentration compactness principle, bounded sequence, convergence, system of elliptic equations, critical exponent.

\section{REFERENCES}

[1] B. Abdellaoui, V. Felli, I. Peral, Existence and nonexistence for quasilinear equations involving the p-Laplacian, Boll. Unione Mat. Ital. Sez. B, 9 (2006), 445-484.

[2] B. Abdellaoui, V. Felli, I. Peral,Some remarks on systems of elliptic equations doubly critical in the whole $\mathbb{R}^{N}$, Calc. Var. Partial Differential Equations, 34 (2009), 97-137.

[3] C. O. Alves, D. C. De Morais Filho, M. A. S. Souto, On systems of elliptic equations involving subcritical or critical Sobolev exponents, Nonlinear Anal., 42 (2000), 771-787.

[4] R. B. Assuncao, P. C. CARriao, O. H. MiYAGaki, Critical singular problems via concentrationcompactness lemma, J. Math. Anal. Appl., 326 (2007), 137-154.

[5] T. BARTSCH, S. PENG, Z. Zhang, Existence and non-existence of solutions to elliptic equations related to the Caffarelli-Kohn-Nirenberg inequalities, Calc. Var. Partial Differential Equations, 30 (2007), 113-136.

[6] M. Bouchekif, Y. Nasri, On a singular elliptic system at resonance, Ann. Mat. Pura. Appl., 189 (2010), 227-240.

[7] H. BREZIs, E. LIEB, A relation between pointwise convergence of functions and convergence of functionals, Proc. Amer. Math. Soc., 88 (1983), 486-490.

[8] L. Caffarelli, R. Kohn, L. NirenberG, First order interpolation inequality with weights, Compos. Math., 53 (1984), 259-275.

[9] D. CAO, P. HAN, Solutions to critical elliptic equations with multi-singular inverse square potentials, J. Differential Equations, 224 (2006), 332-372.

[10] V. FELLI, S. TERRACINI, Elliptic equations with multi-singular inverse-square potentials and critical nonlinearity, Comm. Partial Differential Equations, 31 (2006), 469-495.

[11] N. Ghoussoub, C. YuAn, Multiple solutions for quasi-linear PDEs involving the critical Sobolev and Hardy exponents, Trans. Amer. Math. Soc., 352 (2000), 5703-5743.

[12] P. HAN, The effect of the domain topology on the number of positive solutions of some elliptic systems involving critical Sobolev exponents, Houston J. Math., 32 (2006), 1241-1257.

[13] G. Hardy, J. Littlewood, G. Polya, Inequalities, reprint of the 1952 edition, Cambridge Math. Lib., Cambridge University Press, Cambridge, 1988.

[14] Y. HUANG, D. KANG, On the singular elliptic systems involving multiple critical Sobolev exponents, Nonlinear Anal., 74 (2011), 400-412.

[15] E. JANnelLI, The role played by space dimension in elliptic critcal problems, J. Differential Equations, 156 (1999), 407-426.

[16] D. KAnG, Quasilinear systems involving multiple critical exponents and potentials, Comm. Pure Appl. Anal., 2012, in press. 
[17] P.L.Lions, The concentration compactness principle in the calculus of variations, the limit case (I), Rev. Mat. Iberoamericana, 1, (1) (1985), 145-201.

[18] P. L. Lions, The concentration compactness principle in the calculus of variations, the limit case(II), Rev. Mat. Iberoamericana, 1, (2) (1985), 45-121.

[19] Z. LIU, P. HAN, Existence of solutions for singular elliptic systems with critical exponents, Nonlinear Anal., 69 (2008), 2968-2983.

[20] J. LonG, J. YANG, Existence results for critical singular elliptic systems, Nonlinear Anal., 69 (2008), 4199-4214.

[21] S. Peng, Remarks on singular critical growth elliptic equations, Discrete Contin. Dyn. Syst., 14 (2006), 707-719.

[22] F. Rellich, Perturbation theory of eigenvalue problems, Gordon and Breach, New York, 1969.

[23] S. TERRACINI, On positive solutions to a class of equations with a singular coefficient and critical exponent, Adv. Differential Equations, 2 (1996), 241-264. 